\title{
Role of Different Thymus Essential Oils on Feeding Performance of Leptinotarsa decemlineata Say, 1824 (Chrysomelidae: Coleoptera)
}

\author{
Çağrı Bekircan ${ }^{1, *}$, Mustafa Cüce ${ }^{1}$, Tuba Bekircan ${ }^{1}$, Onur Tosun ${ }^{2}$ \\ ${ }^{1}$ Department of Biology, Faculty of Sciences, Karadeniz Technical University, Turkey \\ ${ }^{2}$ Department of Crop and Animal Production, Junior Technical College of Alucra Turan Bulutcu, Giresun University, Turkey
}

Copyright (C) 2015 Horizon Research Publishing All rights reserved.

\begin{abstract}
The Colorado potato beetle, Leptinotarsa decemlineata Say, 1824 (Chrysomelidae: Coleoptera), is a major problem for conventional potato production in all over the world. Bioactive molecules that originated from plants, have long been claimed as alternatives to synthetic chemicals for pest management Similarly, we investigated antifeedant effect of essential oils obtained from three different Lamiaceae species; Thymus transcaucasicus RONNIGER, Thymus pseudopulegioides KLOKOV and DES.-SHOST, Thymus leucotrichus HAL. against L. decemlineata Say, 1824 (Chrysomelidae: Coleoptera) larvae. T. leucotrichus showed the most powerful and weakest antifeedant effect of the three plant species in different doses $(\mathrm{r}=0.409, \mathrm{P}<0.01)$. The highest AFI value (AFI $=65.548)$ was obtained on the third day at $2000 \mathrm{ppm}(\mathrm{P}<0.05)$ and the lowest AFI value was measured on the second day at $1000 \mathrm{ppm}(\mathrm{AFI}=0.560)$. According to these results, T. leucotrichus essential oil is the most effective phytochemical against $L$. decemlineata larvae.
\end{abstract}

Keywords Antifeedant, Pest, Leptinotarsa decemlineata, Lamiaceae, Biological Control

\section{Introduction}

The Colorado potato beetle, Leptinotarsa decemlineata Say, 1824 (Chrysomelidae: Coleoptera), is a most serious pest insect on solanaceous crops; especially potato, in all over the world (Metcalf and Metcalf, 1993; Webber and Ferro, 1994)[8,15]. The adult and larvae of potato beetles cause severe economic losses with consume foliage of host plants (Gökçe et al., 2006)[4]. To prevent the crop losses chemical pesticides has been used extensively all over the world for managed this beetle. However, these applications bring lots of undesirable situations with together such as resistance development (Mota-Sanchez et al., 2000)[9]. In recent years, interest has grown for the search of alternative control methods for managed this beetle. Because of this conception, bioactive molecules that originated from plants, have long been touted as alternatives to synthetic chemicals for pest management (Santana et al., 2012)[13]. Phytochemicals which are used for managed to pest, are show their effect with different ways like a feeding inhibition (Klepzig and Schlyter, 1999; Wheeler and Isman, 2001)[7,16], growth retardation (Breuer and Schmidt, 1995)[2] and etc. At the same time, these chemicals do not have any side effect for human and environment, in addition pest cannot develop resistance against these compounds (Prakash and Rao, 1997)[10].

In this study, antifeedant properties of three different Lamiaceae plants essential oils; Thymus leucotrichus HAL., Thymus pseudopulegioides KLOKOV and DES.-SHOST and Thymus transcaucasicus RONNIGER were researched against the L. decemlineata Say. larvae.

\section{Material and Methods}

\section{Collection of test insects}

Larvae of $L$. decemlineata were collected from the vicinity of Trabzon, Turkey, during April to June in 2013. When the larvae were taken to the laboratory, $4^{\text {th }}$ instar larvae were separated and placed in plastic boxes for experiment.

\section{Plant Materials}

Plant materials were collected during 2012 to 2013 from the vicinity of Trabzon, Giresun, Bayburt and Rize in Turkey. Fresh plant materials were air-dried in shade condition and fragmented. Essential oils were obtained from the following plants: T. transcaucasicus, $T$. pseudopulegioides and $T$. leucotrichus with Clevenger. Then each essential oil was weighed and stored at $4^{\circ} \mathrm{C}$ until used.

\section{Antifeedant Test}


A no choice test was set up with 3 replicates for each test dose and replicated over 3 days. Each test group was set up with petri dishes $\left(9 \mathrm{~cm}\right.$ in diam.) each including 5 larvae $\left(4^{\text {th }}\right.$ instar) and wet filter paper in the center. One untreated control was also set up. Test dose were prepared from the stock essential oils by further dilution in 50\% methanol in $\mathrm{H}_{2} \mathrm{O}$ to produce five different concentrations: 250, 500, 1000, 2000, $4000 \mathrm{ppm}$. Leaf discs were prepared from potato leaves using a cork borer and weighed before the test. Each leaf discs were immersed in the test solution while fully covered. In addition, control leaf discs were immersed in $50 \%$ methanol in $\mathrm{H}_{2} \mathrm{O}$ solution and all discs were left at room temperature for $3 \mathrm{~min}$ to let the solvent evaporate. Then, each disc was placed in petri dishes and all test groups placed in growth chamber (BINDER KBWF720) $\left(25 \pm 1^{\circ} \mathrm{C}\right.$ and L16: D8 photoperiod). After $4 \mathrm{~h}$, the remnants of leaf discs were collected and dried separately at room temperature to a constant weight. This process was repeated for each of the three treatment days. The amount of food consumed was calculated depending on the initial fresh weight of each disc and the dry weight of its remnants. The antifeedant index was calculated according to; $\mathrm{AFI}=[(\mathrm{C}-\mathrm{T}) /(\mathrm{C}+\mathrm{T})] \times 100$ formula (Sadek, 2003); C as the consumption of control discs and $\mathrm{T}$ the consumption of treated discs. The food consumed by the 5 larvae that were given control discs were averaged, and the means were used as $\mathrm{C}$ for the calculations of the AFI for each observed $\mathrm{T}$.

\section{Statistical Analysis}

The antifeedant indices at different treatments were evaluated using an analysis of ANOVA followed by Duncan test for multiple-comparison where significant differences were observed. A Pearson correlation coefficient test was carried to determine the AFI-Day and AFI-Dose relations between the treatments. All these analysis performed with SPSS version 21.0 for Windows (Yang, 2014)[17].

\section{Results}

In this study, antifeedant index (AFI) values of each essential oils were calculated according to doses at the end of the three treatment days. Dose - Days relation analysis was performed according to these data with Pearson correlation coefficients test (Table 1). According to this test and graphics the highest AFI value was measured on the third day at $2000 \mathrm{ppm}$ dose $(\mathrm{AFI}=65.548)$ and the lowest AFI value was measured on the second day at $1000 \mathrm{ppm}$ dose $(\mathrm{AFI}=0.560)$ with treatment of $T$. leucotrichus (Fig. 1). In addition; on the first day, there was strong positive correlation between dose and AFI indices $\left[1^{\text {th }}\right.$ day; $r=0.959$, $\mathrm{P}<0.01$ ] (Table 1). Moreover, during the three days, the treatment of $T$. leucotrichus showed the most powerful antifeedant effect of the three plant species $(\mathrm{r}=0.409, \mathrm{P}<$ $0.01)$.

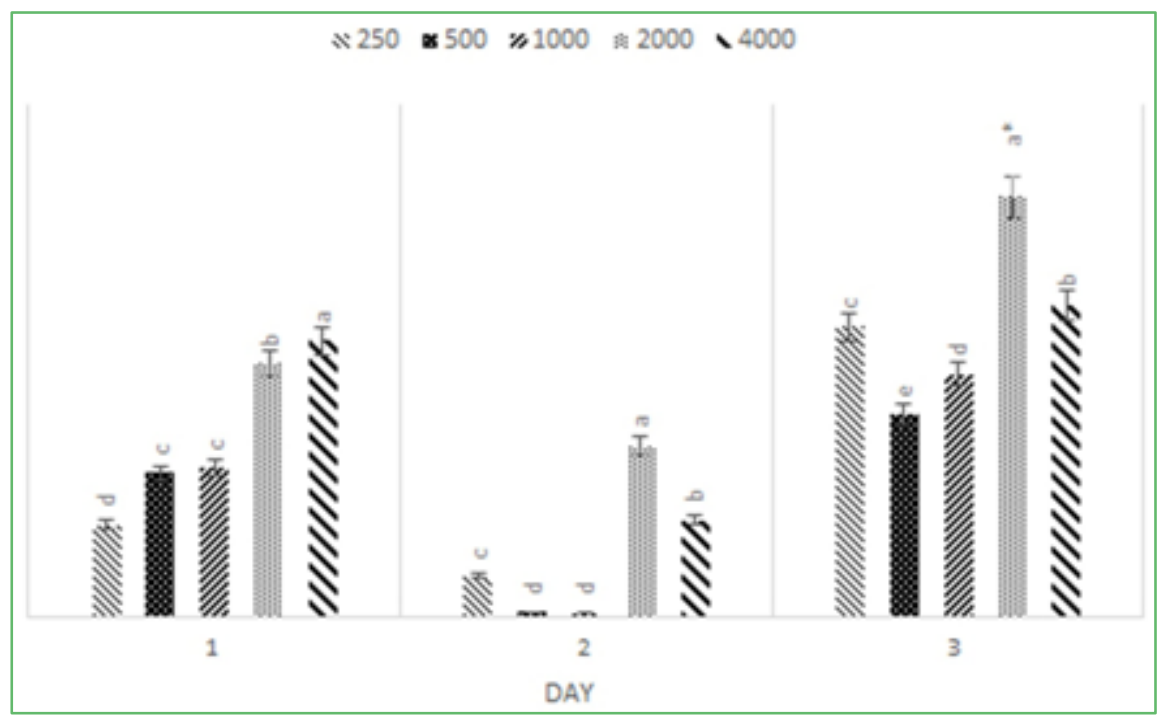

Figure 1. Effect of essential oil of T. leucotrichus on L. decemlineata larvae according to doses and days. * show the most effective AFI value between doses for all days

Table 1. Pearson correlation coefficients between essential oils calculated for AFI indices of L. decemlineata

\begin{tabular}{|c|c|c|c|c|c|c|c|c|c|}
\hline & \multicolumn{3}{|c|}{ T. transcaucasicus } & \multicolumn{3}{|c|}{ T. pseudopulegioides } & \multicolumn{3}{|c|}{ T. leucotrichus } \\
\hline & $1^{\text {th }}$ Day & $2^{\text {th }}$ Day & $3^{\text {th }}$ Day & $1^{\text {th }}$ Day & $2^{\text {th }}$ Day & $3^{\text {th }}$ Day & $1^{\text {th }}$ Day & $2^{\text {th }}$ Day & $3^{\text {th }}$ Day \\
\hline T. transcaucasicus & 0.374 & $0.831 * *$ & -0.487 & & & & & & \\
\hline T. pseudopulegioides & & & & 0.040 & -0.328 & $-0.738 * *$ & & & \\
\hline T. leucotrichus & & & & & & & $0.959 * *$ & $0.615^{*}$ & 0.498 \\
\hline $1^{\text {th }}$ Day & 1 & -0.183 & $-0.835 * *$ & 1 & -0.491 & -0.225 & 1 & $0.754 * *$ & $0.623 *$ \\
\hline $2^{\text {th }}$ Day & -0.183 & 1 & -0.079 & -0.491 & 1 & -0.005 & $0.754 * *$ & 1 & $0.958 * *$ \\
\hline $3^{\text {th }}$ Day & $-0.835 * *$ & -0.079 & 1 & -0.225 & -0.005 & 1 & $0.623 *$ & $0.958 * *$ & 1 \\
\hline
\end{tabular}

** Correlation is significant at the 0.01 level (2-tailed)

* Correlation is significant at the 0.05 level (2-tailed) 


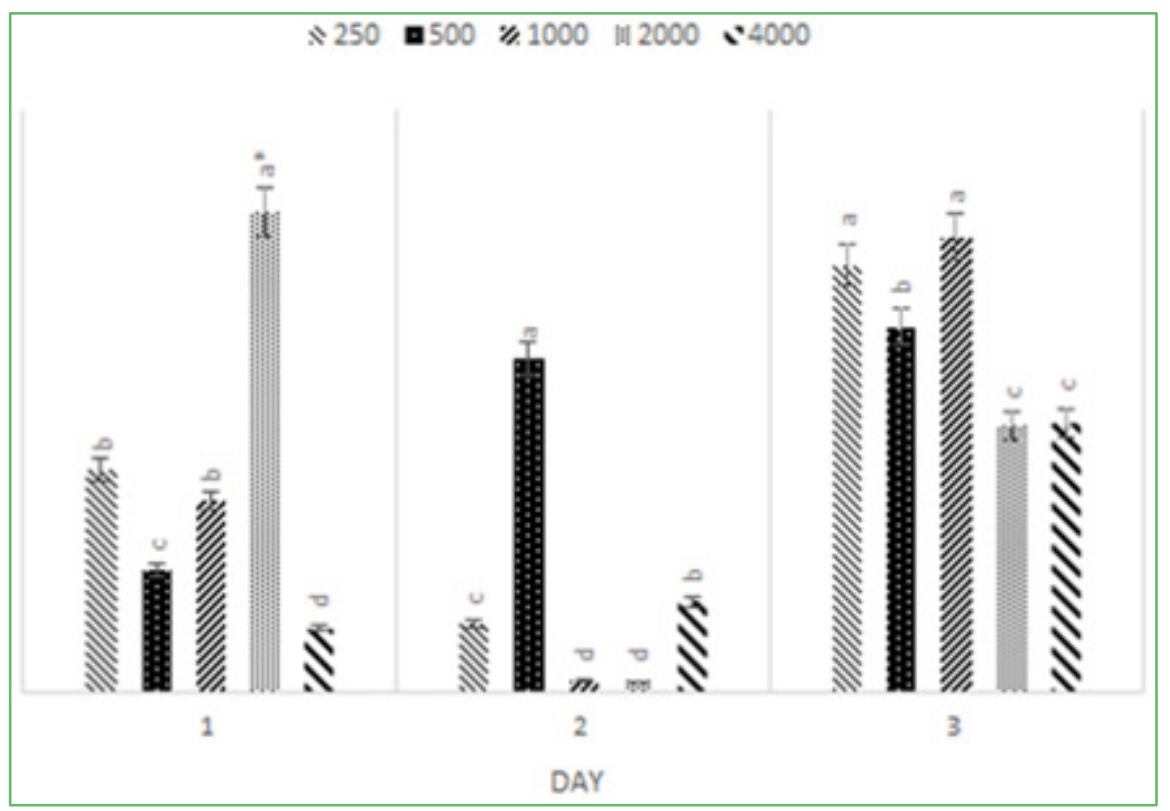

Figure 2. Effect of essential oil of T. pseudopulegioides on L. decemlineata larvae according to doses and days. * show the most effective AFI value between doses for all days

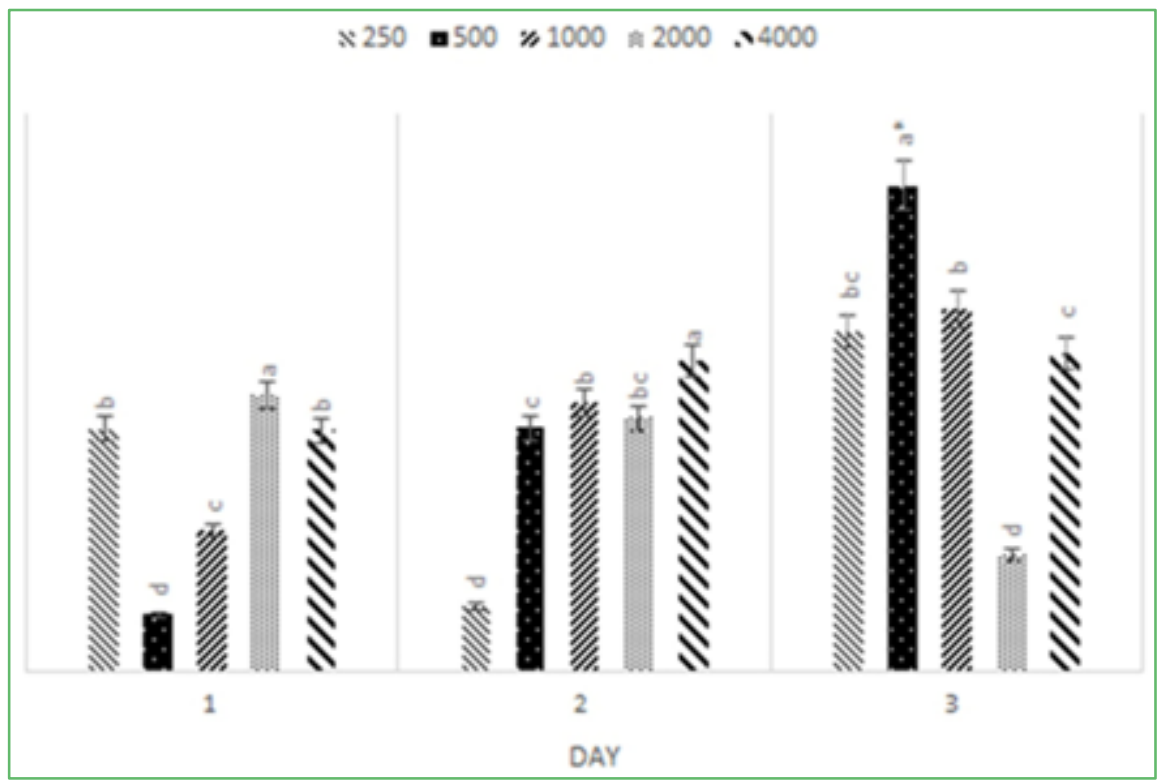

Figure 3. Effect of essential oil of T. transcaucasicus on L. decemlineata. larvae according to doses and days. * show the most effective AFI value between doses for all days

For T. pseudopulegioides, while it reached the highest AFI value on first day with $2000 \mathrm{ppm}$ dose $(\mathrm{AFI}=41.177)$, the lowest AFI value was observed on second day $(\mathrm{AFI}=1.014)$ (Fig. 2). At the same time, on the third day, there was negative correlation between dose and AFI indices $\left[3^{\text {th }}\right.$ day; $\mathrm{r}$ $=-0.738, \mathrm{P}<0.01]$.

$T$. transcaucasicus treatment was the most remarkable with in the tree treatments. Because 500 ppm dose, its AFI indices increased day by day. In addition, the lowest and highest AFI indices were observed on the first and third days at $500 \mathrm{ppm}$ dose $\left[1^{\text {th }}\right.$ day; $\mathrm{AFI}=5.023,3^{\text {th }}$ day; $\left.\mathrm{AFI}=43.624\right]$ (Fig. 3). Other notable result which relevant to $T$. transcaucasicus treatment was, on second day, there was strong positive correlation between dose and AFI indices $\left[2^{\text {th }}\right.$ day; $\mathrm{r}=0.831, \mathrm{P}<0.01]$

\section{Discussion}

The Colorado potato beetle, L. decemlineata Say, 1824 (Chrysomelidae: Coleoptera), is a major problem for conventional potato production in all over the world. And humankind intensively use synthetic chemical insecticides for many years to overcome this problem (Hare, 1990)[6]. But this approach brings lots of problem with together as a resistance development, environmental pollution and etc. 
(Bekircan et al., 2014)[1]. However, nature offers lots of alternative compounds instead of synthetic chemical insecticides. Because most plants develop defense system against herbivore with using secondary metabolites (Taiz and Zeiger, 2010)[14] and Lamiaceae family members come one of the most important groups that have bioactive compounds which can be used against pest (Regnault-Roger et al., 1993)[11]. So this study was designed according to this knowledge and choose especially three Thymus species which were almost never studied in terms of antifeedant features before. In literature, there is only one report was published in 2014 by Bekircan and friends for investigated to antifeedant properties of these three species against the Agelastica alni L. larvae. But there is no study related to these Thymus species which for conducted to determine antifeedant effects on L. decemlineata. According to present study, all test plants showed antifeedant effect on $L$. decemlineata larvae and $T$. leucotrichus showed the most powerful antifeedant effect of the three plant species (AFI = $65.548 ; \mathrm{r}=0.409, \mathrm{P}<0.01)$.

\section{REFERENCES}

[1] Bekircan, Ç., M. Cüce, A. Sökmen 2014. Antifeedant Activity of the Essential Oils from Four Different Lamiaceae Species against Agelastica alni L. (Coleoptera: Chrysomelidae). Advances in Zoology and Botany, 2: 57 62.

[2] Breuer, M. and G.H. Schmidt, 1995. Influence of a short period treatment with Melia azedarach extract on food intake and growth of the larvae of Spodoptera frugiperda (J. E. Smith) (Lep., Noctuidae). J Plant Dis Protect 102: 633-654.

[3] Casagrande, R.A. 1987. The Colorado potato beetle: 125 years of mismanagement. Bull Entomol Soc Am, 33: 142150.

[4] Gökçe, A., R. Isaacs and M.E. Whalon, 2006. Behavioural response of Colorado potato beetle (Leptinotarsa decemlineata) larvae to selected plant extracts. Pest Management Science, 62: 1052-1057.

[5] Grafius, E. 1997. Economic impact of insecticide resistance in the Colorado potato beetle (Coleoptera: Chrysomelidae) on the Michigan potato industry. J Econ Entomol, 90: 11441151 .

[6] Hare, J.D. 1990. Annual Review of Entomology, 35: 81.

[7] Klepzig, K.D. and F. Schlyter, 1999. Laboratory evaluation of plant derived antifeedants against the pine weevil Hylobius abietis (Coleoptera: Curculionidae). J Econ Entomol 92: 644650 .

[8] Metcalf, R.L. and R.A. Metcalf, 1993. Destructive and Useful Insects. Their Habits and Control, 5th Edn. McGraw-Hill Book Co., New York, NY, pp. 1443-1445.

[9] Mota-Sanchez, D., M.E. Whalon, E. Grafius and R. Hollingworth, 2000. Resistance of Colorado potato beetle to imidacloprid. Resistant Pest Management Newsletter, 11: 3134.

[10] Prakash, A. and J. Rao, 1997. Botanical pesticides in agriculture. CRC Press Inc, USA, p. 461.

[11] Regnault-Roger, C., A. Hamraoui, M. Holeman, E. Theron, R. Pinel 1993. Insecticidal effect of essential oils from Mediterranean plant upon Acanthoscelides obtectus Say (Coleoptera, Bruchidae), a pest of kidney bean (Phaseolus vulgaris). J Chem Ecol 19: 1233-1244.

[12] Sadek, M.M., 2003. Antifeedant and toxic activity of Adhatoda vasica leaf extract against Spodoptera littoralis (Lep., Noctuidae). J Appl Entomol 127: 396-404.

[13] Santana, O., M. Reina, B.M. Fraga, J. Sanz and A. Gonzalez-Coloma, 2012. Antifeedant Activity of Fatty Acid Esters and Phytosterols from Echium wildpretii. Chemistry \& Biodiversity 9: 567-576.

[14] Taiz, L. and E. Zeiger 2010. Plant Physiology, 5th edition. Sinauer Associates, Inc., Sunderland, MA.

[15] Webber, D.C. and D.N. Ferro, 1994. Colorado potato beetle: diverse life history poses challenge tomanagement, In Advances in Potato Pest Biology and Management. ed. Zehnder, G.W., M.L. Powelson, R.K. Jansson and K.V. Raman, , APS Press, St Paul, MN, pp. 54-70.

[16] Wheeler, D.A. and M.B. Isman, 2001. Antifeedant and toxic activity of Trichilia americana extract against the larvae of Spodoptera litura. Entomol Exp Appl 98: 9-16.

[17] Yang, Y.H. 2014. A Path Analysis on Factors Influencing Second Primary Cancer Screening Practices in Stomach, Colon, and Breast Cancer Survivors. Journal of Korean Academy of Nursing, 44 (2): 139-148. 